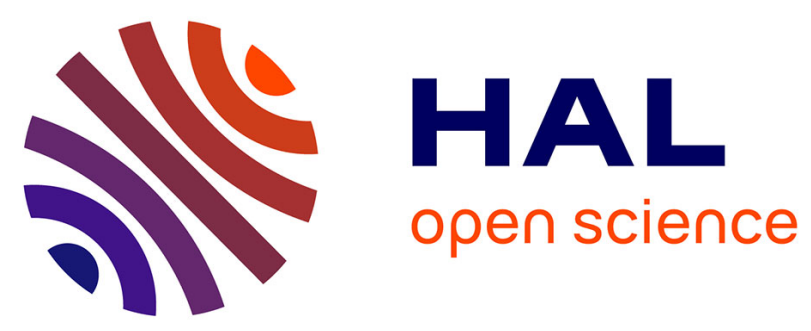

\title{
Assessment of the dominant factors during hydroprocessing stabilization
}

Ngoc Yen Phuong Cao, Benoît Celse, Denis Guillaume, Isabelle Guibard, Joris W. Thybaut

\section{- To cite this version:}

Ngoc Yen Phuong Cao, Benoît Celse, Denis Guillaume, Isabelle Guibard, Joris W. Thybaut. Assessment of the dominant factors during hydroprocessing stabilization. Computer Aided Chemical Engineering, 2019, pp.1129-1134. 10.1016/B978-0-12-818634-3.50189-2 . hal-02479587

\section{HAL Id: hal-02479587 \\ https: / hal-ifp.archives-ouvertes.fr/hal-02479587}

Submitted on 14 Feb 2020

HAL is a multi-disciplinary open access archive for the deposit and dissemination of scientific research documents, whether they are published or not. The documents may come from teaching and research institutions in France or abroad, or from public or private research centers.
L'archive ouverte pluridisciplinaire HAL, est destinée au dépôt et à la diffusion de documents scientifiques de niveau recherche, publiés ou non, émanant des établissements d'enseignement et de recherche français ou étrangers, des laboratoires publics ou privés. 


\title{
Assessment of the dominant factors during hydroprocessing stabilization
}

\author{
Ngoc Yen Phuong Cao, ${ }^{\mathrm{a}}$ Benoit Celse, ${ }^{\mathrm{a},{ }^{*}}$ Denis Guillaume, ${ }^{\mathrm{a}}$ Isabelle Guibard, ${ }^{\mathrm{a}}$ \\ Joris W.Thybaut ${ }^{\mathrm{b}}$ \\ ${ }^{a}$ IFP Energies nouvelles, Rond-point de l'échangeur de Solaize, BP 3, 69360 Solaize, \\ France \\ ${ }^{b}$ Ghent University, Laboratory for Chemical Technology, Technologiepark 914, Ghent, \\ B-9052, Belgium \\ benoit.celse@ifp.fr
}

\begin{abstract}
Establishing the steady state in hydrotreating process requires several days, leading to long experimentation times in order to obtain sufficient steady-state data for kinetic modelling. However, during the evolution towards this steady state, effluent analyses are already carried out at regular time intervals to determine whether the steady state has been reached and to ensure that the reaction is under control. In this paper, the stabilization time was assessed by using experimental data during these transient conditions. The stabilization evolution is supposed to follow a first-order response. A characteristic time for stabilization $\tau$ was defined. A linear model with interaction for $\tau$ prediction was developed. It was found that a higher LHSV leads to a quicker stabilization. The extent of the impact of LHSV on $\tau$ depends on the feed resin content, i.e., the polar components with high molecule weight. A direct relationship between reactor pressure and stabilization time was found. Temperature is not a dominant factor. Stabilization of spent catalyst depends on the previous operating conditions.

Moreover, online transient data can be used in order to predict, from the first two experimental points and $\tau$ calculated by the model, the future steady-state value. By testing against new data with other feedstocks, the model has been found to provide a good prediction of the stabilization evolution and the steady-state hydrotreating performance. If this value is far from the target, operators can change the operating condition without waiting for stabilization.
\end{abstract}

Keywords: hydrocarbon, hydrotreating, kinetic modelling, reactor, stabilization, transient data.

\section{Introduction}

Hydrotreating is a catalytic conversion process in petroleum refining, among others for removing impurities such as nitrogen and sulphur compounds from hydrocarbon streams. A kinetic model is a significant asset in, not to say essential for the adequate design and simulation of such a process (Becker et al., 2015). It is usually developed based on experimental data acquired at steady-state conditions. One of the main challenges of hydrotreating process is that establishing this steady state typically requires several days, leading to long experimentation times in order to obtain sufficient 
data for kinetic modelling. However, during the transient phase towards the steady state, effluent analyses are already carried out at regular time intervals to detect the steady state and to ensure that the reaction is under control. These available transient data are currently not used for kinetic modelling because the stabilization behaviour is not well understood.

The aim of this work is, first, to get a better understanding of the stabilization behaviour during these transient conditions and secondly, to use these transient data to predict the steady-state reaction performance. If this value is far from a target, the operators can change the operating condition without waiting for stabilization and without the use of a complex model.

\section{Materials \& Methods}

The experimental data are acquired using the IFPEN Hydrotreatment (HDT) pilot plant operating in a continuous manner. The total catalyst volume in the reactor amounts to $50 \mathrm{~cm}^{3}$. Operating conditions are adjusted after having reached the steady state corresponding with the previous operating conditions. The acquired data cover 11 Vacuum Gas Oil (VGO) feeds over two catalysts. Operating conditions were chosen to cover a wide range for the VGO HDT process: Liquid Hourly Space Velocities (LHSV) from 0.5 to $4 \mathrm{~h}^{-1}$, temperature from 350 to $410{ }^{\circ} \mathrm{C}$ and total pressure between 50 and 140 bar. The provided data are the 'liquid product nitrogen content' $(\mathrm{N})$ with time on stream (TOS), totalling 920 measurements, see Figure 1. A series of points corresponding to one experimental run is called one 'episode'. Figure 1 shows 7 episodes corresponding to 42 data points during around 45 days.

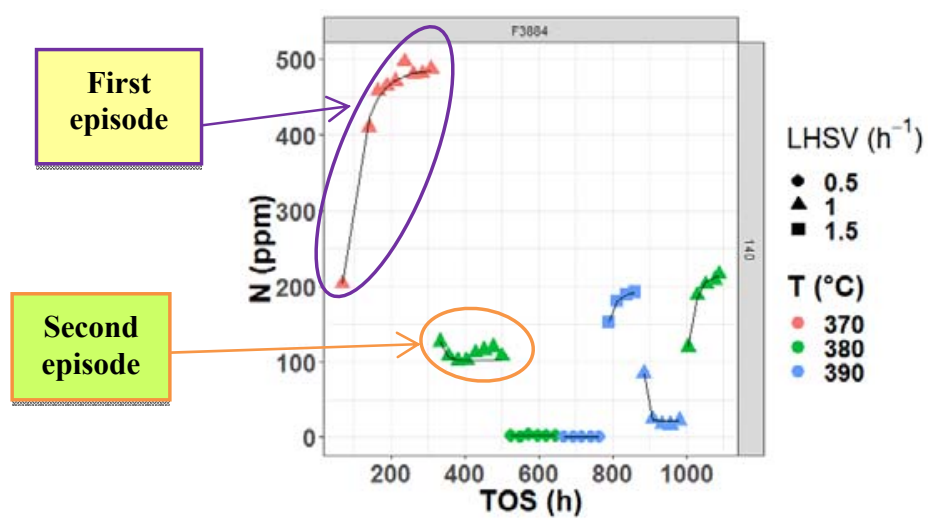

Figure 1. Data representation ( $\mathrm{P}=140 \mathrm{bar}$, point: experimental data, solid line: model fitting Equation (1))

A hydrodynamics study on the pilot plant has been carried out using a tracer technique to estimate the stabilization time purely due to hydrodynamic. The objective is to identify whether the stabilization time is determined by hydrodynamic or kinetic phenomena. 
Exploratory data analysis (Tukey, 1977) is applied to our available data to assess the stabilization evolution. It resulted in a first-order transfer function as shown in Equation (1).

$N=N_{\text {init }}+\left(N_{\text {final }}-N_{\text {init }}\right) \cdot\left(1-\exp \left(\frac{-\left(T O S-T S_{\text {init }}\right)}{\tau}\right)\right)$

Where $\mathrm{N}$ is the liquid product nitrogen at a specific time on stream (ppm); $\mathrm{N}_{\text {init }}$ is the liquid product nitrogen corresponding to the first experimental point of episode (ppm); $\mathrm{N}_{\text {final }}$ is the last experimental point of episode (ppm); TOS is the time on stream (h); $\mathrm{TOS}_{\text {init }}$ is the time on stream corresponding to the first experimental point of episode (h) and $\tau$ is the characteristic time of the episode $(\mathrm{h})$.

The characteristic time $\tau$ of each episode presented in the equation is estimated via nonlinear least-squares (solid line in Figure 1).

A multiple linear regression with interaction technique is then used for $\tau$ prediction to evaluate the phenomena underlying the transient data. The general linear model with interaction is illustrated in Equation (2):

$$
\tau=a_{1} x_{1}+a_{2} x_{2}+a_{12} x_{1} x_{2}+\ldots+b
$$

Where $\mathrm{x}_{1}, \mathrm{x}_{2}$ are the input variables, which can be LHSV, temperature, pressure or feed properties such as organic nitrogen content, organic sulphur content, resin content in feed, etc.; $\mathrm{x}_{1} \mathrm{x}_{2}$ is the interaction term between $\mathrm{x}_{1}$ and $\mathrm{x}_{2} ; \mathrm{a}_{1}, \mathrm{a}_{2}, \mathrm{a}_{12}, \ldots$ and $\mathrm{b}$ are the coefficients.

The most influential input variables of the model are determined via variable selection technique called 'leaps' (Furnival and Wilson, 1974). Fitting linear model and nonlinear model was done by using respectively ' $\mathrm{lm}$ ' and 'nls' function in 'stats' package in R software. Variable selection was carried out in R by using 'leaps' package obtained from CRAN repository (Lumley, 2017).

The model is then tested against new data with other feedstocks. For each episode, $\tau$ is predicted by the model. Knowing $\tau$ and the first two points of the episode, it is possible to predict the evolution of the episode as well as the Nitrogen content at steady state calculated via Equation (3) which is developed from Equation (1). The leftover data of the episode are used to validate the model. If the predicted steady-state value is far from the target, the operating condition can be adjusted without waiting for stabilization.

$$
N_{\text {final }}=\frac{N-N_{\text {init }}}{1-\exp \left(\frac{-\left(T O S-T O S_{\text {init }}\right)}{\tau}\right)}+N_{\text {init }}
$$




\section{Results}

The hydrodynamic response to a tracer step reached steady state significantly faster than the stabilization of the HydroDeNitrogenation (HDN) behaviour. Hence, chemical phenomena are involved in the latter.

Stabilization was found to follow a first-order model, which is similar to the observation of Sau et al. (2005) in the study of effect of organic nitrogen compounds on hydroprocessing reaction. The characteristic time $\tau$ reflects the time required to reach this steady state. First episodes take more time to stabilize than other episodes. The model was applied on two similar HDT catalysts (Catalyst A and B). Two linear models for $\tau$ were built; one for first episodes (model M1) and another for other episodes (model M2).

Model M1 was obtained with a $\mathrm{R}^{2}$ of 0.83 , as shown in the left side of Figure 2. It consists of three variables (LHSV, pressure, resin of feed) and one interaction term LHSV*resin, which are selected by the leaps algorithm. An inverse relationship between LHSV and $\tau$ was found. Temperature is not a dominant factor. These two results are coherent with Elizalde et al. (2016) who studied the dynamic behaviour of hydrocracking using the continuous kinetic lumping approach. A direct relationship between pressure and $\tau$ was observed. The interaction term shows that the impact of LHSV on $\tau$ depends on the value of feed resin, i.e., the polar components with high molecular weight. The resin in VGO can contain nitrogen.
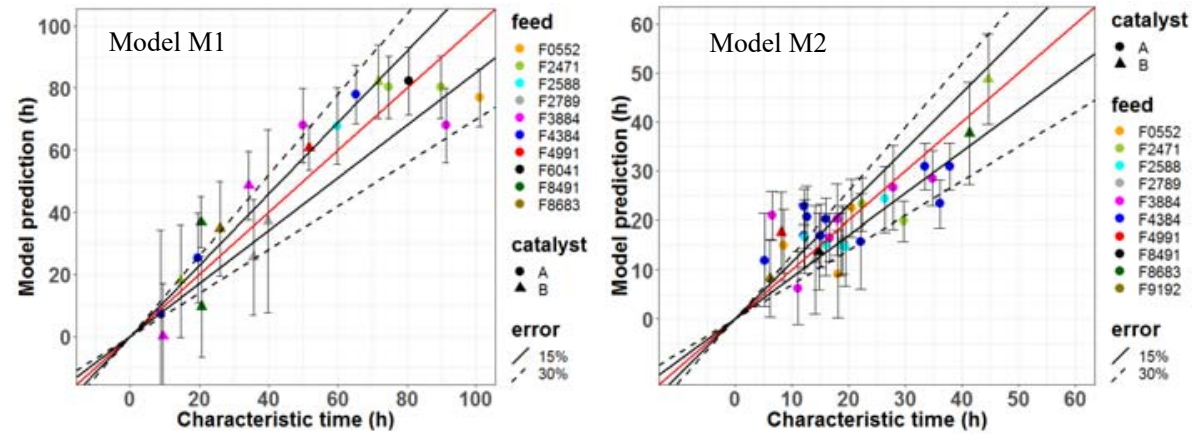

Figure 2. Parity plot with $95 \%$ confidence interval for $\mathrm{M} 1\left(\right.$ left, $\left.\mathrm{R}^{2}=0.83\right)$ and $\mathrm{M} 2$ (right, $\mathrm{R}^{2}=$ $0.66)$

However, the stabilization of other episodes seems more complex. The parity plot for model M2 is shown in the right side of Figure 2. The latter includes seven input variables $\left(\mathrm{LHSV}_{\text {exp }}, \mathrm{LHSV}_{\text {pre }}, \mathrm{T}_{\text {pre }}, \frac{L H S V_{\text {exp }}}{L H S V_{\text {pre }}}, \frac{L H S V_{\text {pre }}}{L H S V_{\text {exp }}}, \mathrm{LHSV}_{\text {exp }}{ }^{*}\right.$ resin, $\mathrm{S}_{\text {feed }}$ );

where $\mathrm{LHSV}_{\text {exp }}$ is the experimental LHSV of the episode; LHSV pre and $\mathrm{T}_{\text {pre }}$ are respectively LHSV and temperature of the previous episode; resin and $\mathrm{S}_{\text {feed }}$ are respectively resin content and organic sulphur content in the feed. As can be seen, the model relies by not only on the feed and operating conditions but also on the operating conditions of the previous episode. It shows that the transient behaviour of spent catalyst is more difficult to predict than for the fresh catalyst. 
Model was tested by using new data with other feedstocks. $\tau$ is predicted by the model and the steady-state value is estimated via Equation (3). Figure 3 shows two examples of such prediction for first episodes (model M1). The two first points of episode which are used to estimate the steady-state value are shown in circle shape. The remaining data in the episode are represented by triangles. The Nitrogen predicted values are very close to the experimental values. The model can predict quite well the transient behaviour and the steady-state value. This algorithm may be linked to an Advanced Process Control method to reach as fast as possible some Nitrogen targets.
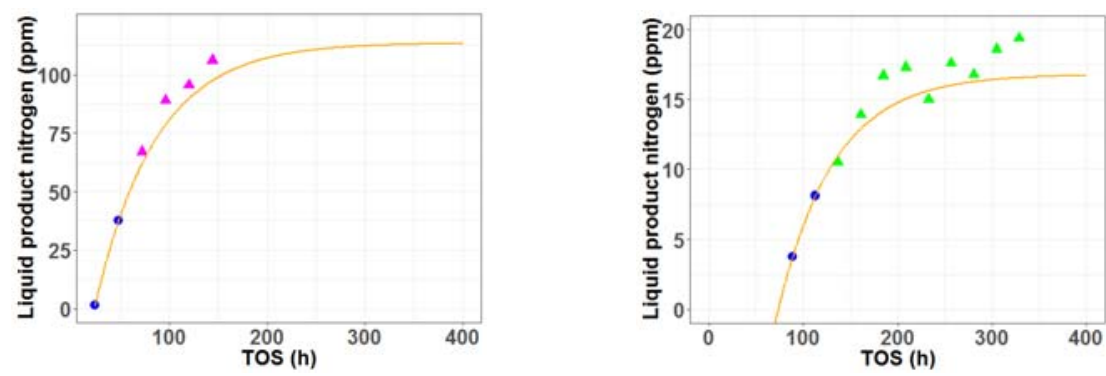

Figure 3. Two examples of the prediction of model M1 (points: experimental data, solid line: model prediction; TOS: time on stream)

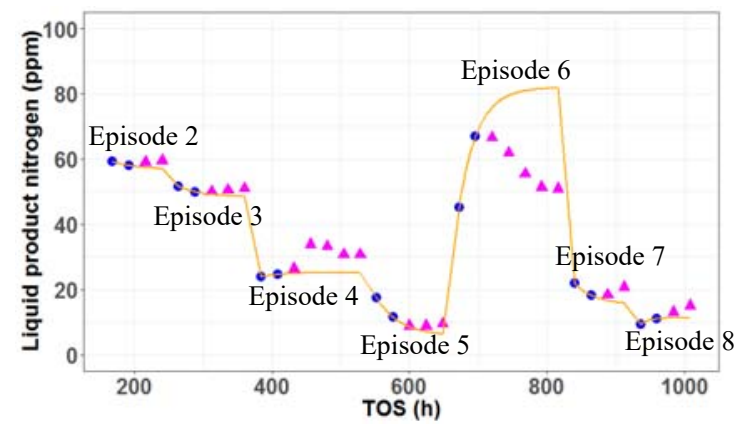

Figure 4. Prediction of model M2 (points: experimental data, solid line: model prediction; TOS: time on stream)

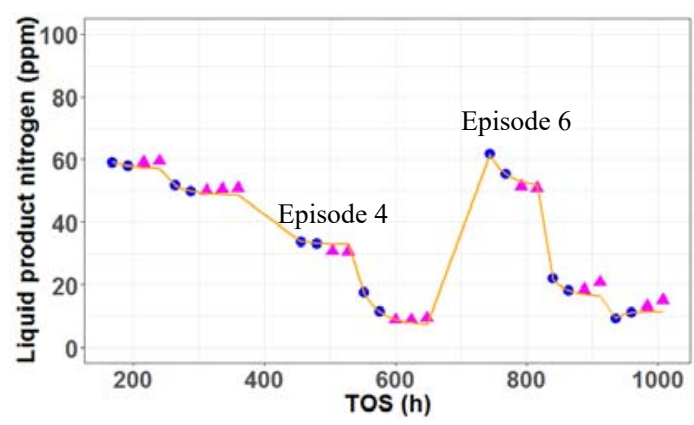

Figure 5. Prediction of model M2 for episode 4 and episode 6 while discarding the first three experimental points of both episodes 
Model M2 (for other episodes) is evaluated and is shown in Figure 4. Model predicts well the evolution of episode 2, 3, 5, 7 and 8. Regarding episode 4 and 6 , it seems that the transient behaviour did not follow a first-order model, which could be explained by the measurement error/experiment problem or the complex behaviour of spent catalyst. The experimentation duration is longer for these both episodes than for the others. It is possible that there was an experiment problem. If the first three points of episode 4 and 6 are discarded, the prediction is more reliable, see Figure 5. This might be investigated in another study.

\section{Conclusions}

Stabilization behaviour is a critical point for hydroprocessing experiments. In this work, transient data of hydrotreating process were used to assess this stabilization. It is shown that the stabilization follows the first-order model. A characteristic time for stabilization $\tau$ was defined. Two models (one for the first episodes, another for the others) were built to calculate the stabilization time and identify the most influential parameters (LHSV, resin of feed, pressure). Good prediction results were obtained, particularly for the first episodes. The stabilization of other episodes is more complicated to predict.

The model can predict the stabilization time and steady-state value from two initial measures. If the predicted steady-state value would be far from the intended target, operators can change the operating condition without waiting for stabilization. This model will be linked with an Advanced Process Control Algorithm.

This model will be also linked to design of experiment algorithm in order to be used to fit kinetic parameters (Celse et al., 2016).

\section{References}

P.J. Becker, B. Celse, D. Guillaume, H. Dulot, V. Costa, 2015, Hydrotreatment modeling for a variety of VGO feedstocks: A continuous lumping approach, Fuel, 139, 133-143.

B. Celse, J.J. Da Costa, V. Costa, 2016, Experimental Design in Nonlinear Case Applied to Hydrocracking Model: How Many Points Do We Need and Which Ones?, International Journal of Chemical Kinetics, 48, 11, 660-670.

I. Elizalde, F. Trejo, J.A.D. Muñoz, P. Torres, J. Ancheyta, Dynamic modeling and simulation of a bench-scale reactor for the hydrocracking of heavy oil by using the continuous kinetic lumping approach, Reaction Kinetics, Mechanisms and Catalysis, 2016, 118, 1, 299-311. DOI: 10.1007/s11144-016-0995-8.

J. J. Faraway, Linear Models with R, Taylor \& Francis Group, New York, United States, 2014.

G. M. Furnival, R.W. Wilson, 1974, Jr, Regressions by Leaps and Bounds, Technometrics, 499511.

T. Lumley, based on Fortran code by A. Miller, 2017, Package 'leaps': Regression subset selection, including exhaustive search, https://cran.r-project.org/web/packages/leaps/leaps.pdf.

R Core Team and contributors worldwide, Package 'stats': R statistical functions.

M. Sau, K. Basak, U. Manna, M. Santra, R. P. Verma, Effects of organic nitrogen compounds on hydrotreating and hydrocracking reactions, Catalysis Today, 2005, 109, 1-4, 112-119. DOI: 10.1016/j.cattod.2005.08.007.

J. W. Tukey, 1977, Exploratory Data Analysis, Addison-Wesley, Reading, MA. 